\title{
Escrituras del yo en la obra poética de Miguel de Unamuno
}

\author{
Berit Callsen \\ (Universität Osnabrück)
}

La poesía de Miguel de Unamuno no circula, sino que circunda el yo lírico, que, a menudo, es un yo autobiográfico.

La hipótesis que formará el punto de partida de las siguientes reflexiones radica en la idea de que no fueron solamente las condiciones sociopolíticas del exilio y de la censura las que impidieron una mayor recepción internacional de la poesía unamuniana; a ello contribuyó también el marcado sustrato autobiográfico que subyace en su lírica. Ya a partir de su lírica temprana, que concibe en Poesías (1907), lo personal recibe un particular trato formal y semántico, densificándose en una escritura del yo. Por su misma celebración de una individualidad expuesta, esta tiende a restringir el radio de su recepción. En la escenificación de una tal escritura del sujeto, Unamuno opera, fundamentalmente, con base en dos claves interrelacionadas entre sí, que son la noción de un trabajo del yo, por un lado, y de la retórica de consejo, por el otro. Ambos componentes figurarán en el centro de los siguientes análisis.

$\mathrm{Al}$ ensimismamiento lírico contribuye, no por último, la polémica antimodernista de Unamuno. Esta, aparte de cerrarse frente a los novedosos impulsos que vienen del otro lado del Atlántico, corrobora, a su vez, un modelo del sujeto ético, tan dinámico como autorreflexivo y autoobservante, que practica un trabajo individual.

Se considera que la obra poética de Unamuno difícilmente se puede estudiar sin tomar en cuenta, por lo menos, algunos textos clave del autor, ficcionales y ensayísticos, que demuestran estrategias poetológicas parecidas en la constitución de una escritura del yo. Considerando el componente transgenérico de su obra ${ }^{1}$ y abordando en ello una pers-

\footnotetext{
${ }^{1}$ Repetidamente, la crítica ha llamado la atención sobre la composición expresamente transgenérica de la obra de Miguel de Unamuno. Véanse, entre otros, Vivanco (1980: 349) y Suárez Miramón (1987b: 10).
} 
pectiva genealógica y comparativa, el estudio se centrará en el análisis de su Cancionero, echando, asimismo, un vistazo a su lírica temprana del libro Poesías, así como a su novela más conocida, Niebla, y a algunos textos ensayísticos del autor. En esta alternación y confluencia dialogada de lírica y prosa, en tanto base empírica de una escritura del yo, se vislumbrará una dinámica propia capaz de ilustrar la continuidad transgenérica de diferentes formas de trabajos y consejos subjetivos en la obra unamuniana.

\section{RETROALIMENTACIONES DE UNA ESCRITURA DEL YO}

En diferentes ocasiones la crítica ha destacado el carácter íntimo de la poesía unamuniana, densificándose en un subjetivismo objetivo que colinda con la autobiografía, el testimonio y el diario. Así, Manuel Alvar afirma que "los poemas, sí, objetivan, pero no para ser contemplados desde lejos, sino para proyectar un subjetivismo, para hacer tantos Unamunos cuantos prosélitos se adhieren a ellos; no infinitas objetivaciones, sino un universo de espíritus concordes" (1975: 43).

En la proyección de quien escribe y se describe, se anuncia aquí, no por último, una escritura del yo que demuestra una cercanía con lo que Ana Suárez Miramón ha caracterizado como el "conceptismo íntimo" (1987c: 36) de la obra unamuniana. Así, es al mismo tiempo una "biografía íntima y externa que traducen sus versos" (1987a:16). En este contexto se ha señalado también una paralela con la escritura de su Diario intimo (1902). ${ }^{2}$

Un breve vistazo a este texto, publicado por primera vez en 1970, nos puede revelar unos primeros indicios de cómo Unamuno mismo definió el núcleo y la finalidad de sus autosondeos, ya sean estos inmersos en versos, diarios o textos ficcionales. Afirma Unamuno:

¡Conócete á [sic] tí mismo! Repítese esto mucho y como á [sic] principio de filosofía lo tiene sabiduría mundana. Pero entiende por ello estudiarse como á [sic] ser extraño, como a mero ejemplar de la humanidad, como á [sic] asunto científico, psicológicamente. El conócete á [sic] ti mismo lo reduce a fría fórmula de conocimiento puramente intelectual, á [sic] ciencia de anatomía y nada más. Pero no á [sic] conocerse como á [sic] tal individuo concreto, vaso de miserias y de pecados, de grandezas y de pequeñeces. (1970: 50)

${ }^{2}$ Además, Ynduráin llama la atención sobre el hecho de que el ciclo de poemas De Fuerteventura a París que Unamuno publica en 1925 se subtitula "Diario íntimo de confinamiento y destierro vertido en sonetos” (véase Ynduráin 1980: 347). 
En la oposición de lo científico y lo concreto, lo abstracto y lo vital, en tanto accesos divergentes al individuo, Unamuno escenifica su propia escritura del yo como vía explorativa que se inclina a conocer y a dar a conocer la idiosincracia de lo que, en su ensayo más célebre, Del sentimiento trágico de la vida, ${ }^{3}$ ha denominado como "hombre de carne y hueso" (1993: 48). Asemejándose al ser vitalista, el hombre de carne y hueso equivale a la figura alegórica del ser ambivalente que reúne en sî una serie de contradicciones y paradojas - "grandezas y pequeñeces", como dice la cita-, al mismo tiempo que las confronta con su entorno. Así, ve en la misma escritura un instrumento no solo para explorar su ser paradójico, sino también para formular los desafíos que enfrenta continuamente. Es esta exteriorización por medio de la palabra escrita la que, en un siguiente paso, posibilita el necesario trabajo y la formación personales.

A partir de estas observaciones, es posible destacar una retroalimentación entre escritura del yo - lo que Foucault ha denominado écriture de $s o i^{4}$ para definir una técnica que consolida el yo a través del acto de escribir- y quehacer literario, sobre todo, poético. Ello se densifica también en el hecho de que, ya a partir de sus Poesías, se hace notar un gesto de diario en el marco de su lírica (por ejemplo, a través de la introducción de fechas al lado de los poemas). Al mismo tiempo, en este entrecruzamiento de lo poético y lo tentativamente aforístico se vislumbra el componente transgenérico de su obra que mencionamos más arriba.

Como se verá, la escritura del yo se concibe, en parte, en una búsqueda de una noción de lo impuro que se codifica para Unamuno en tanto elemento productivo. Lo aleatorio y heterogéneo que le son inherentes se corroboran ex negativo a través de una crítica tajante de la poesía modernista. Así, su polémica antimodernista se insinúa como estrategia para configurar e ilustrar un contramodelo que opera no solamente en lo estético, sino también en lo ético. Este encuentra su núcleo conceptual en la figura ya mencionada del individuo vitalista que se constituye en un constante cambio intrapersonal. A continuación, se trata de echar un breve vistazo al posicionamiento antimodernista de Unamuno tal como se ilustra a través de diferentes ensayos y artículos periodísticos.

${ }^{3}$ En este ensayo Unamuno resemantiza el concepto de la agonía y lo hace funcionar en un sentido productivo en tanto lucha del individuo en su proyecto del trabajo del yo.

${ }^{4}$ Escribir y, más aún, escribir sobre sí mismo equivale, según Foucault, a un elemento del trabajo del yo que adquiere una función ético-poética (cf. Foucault 2007: $140)$. 


\section{LA POLÉMICA UNAMUNIANA EN TORNO AL MODERNISMO}

Entre las reservas que Unamuno formula hacia el modernismo en general y la poesía modernista en específico, el reproche del esteticismo, siendo a su vez síntoma de un percibido individualismo tan separatista como superficial, se ubica, sin duda, en un lugar destacado. Así, a muchos de los modernistas hispanoamericanos, Unamuno los considera "estetas y paganizantes”; según él “[...] se vienen con cosas exóticas y librescas, con fantasmagorías seudohelénicas [...] y amenas superficialidades [...]” (en Chávez 1964: 156). Aquí no se critica solamente la imitación vacía de modelos de la antigüedad europea, sino también la supremacía de la forma sobre el contenido, reproche que repite en Prosa aceitada: "Su lucha no es por buscar pensamientos claros u honrados o brillantes o sugerentes, sino por buscar una lengua nueva, original y preciosa. No piensan en lo que escriben, sino que piensan en cómo han de escribirlo, y, claro está, la cosa les resulta artísticamente detestable" (en Chávez 1964: 156). Es una tendencia a alejarse de la vida común y corriente lo que Unamuno parece detectar en el mismo vocabulario modernista y en la manera de emplearlo.

Sobre esta línea argumentativa, Unamuno se refiere también a Rubén Darío en una de las numerosas cartas que ambos intercambiaron, a pesar de su relación ambivalente. Afirma Unamuno en 1907: “[...] le diré que en usted prefiero lo nativo [...], lo que de un modo o de otro puede ahijarse con viejos orígenes indígenas a lo que haya podido tomar de esa Francia que me es tan poco simpática y aun de esta mi querida España” (en García Blanco 1964: 62). El elogio (a su vez exaltado e idealizante) de lo autóctono Unamuno lo celebra también a partir de su recepción de la literatura gauchesca, género cuya escasa recepción en España tematiza en su estudio entusiasta sobre el poema El gaucho Martín Fierro, de José Hernández. Más que una reseña positiva, este texto publicado en 1894 es un intento de dar a conocer "el gaucho" como otro ejemplo ideal de un "Quijote nacional”. Aquí presenciamos nada menos que una transposición implícita de su doctrina del quijotismo, doctrina que se constituye sobre el mencionado ideal del ser vitalista. Este se mantiene abierto hacia lo incierto, improbable y contingente operando sobre una conjunción de acción e idea, de realidad e imaginación. Con esto, se vislumbraría, como última consecuencia, la imposición de cierta actitud vital para combatir el percibido "vicio del individualismo" elevado y separatista que subyace a la tendencia esteticista del modernismo (cf. Rull 1984: 142).

En breve, es una especie de individualidad artificial la que se presenta como núcleo de la crítica antimodernista de Unamuno. Así, en algunos modernistas no ve "más que extravagancia o afán - afán muy discutible en todo caso - de singularizarse y diferenciarse [...]” (1958: 1303). 
A partir de esta crítica y con base en el quijotismo, fomenta la concepción de otra forma de individualismo que se sugiere, en primer lugar, como trabajo individual: este contramodelo de la individualidad Unamuno lo especifica con el término de "egolatría", denominando una actividad del ser que resulta de una autofocalización prospectiva y que se constituye en función de un constante cambio individual. Aquí se anunciaría, al mismo tiempo, ya un sustrato conceptual existencialista que subyace a la polémica antimodernista de Unamuno.

Este sustrato se va perfilando en textos como "Nuestra egolatría de los del 98”, que se publica en El Imparcial en 1916. En este breve artículo, Unamuno proclama la egolatría como una forma de ser (colectiva) de la generación del 98 que emerge de una "escuela” propia, y dice: "Y enseñamos [...] que cada cual ha de adorar su yo y para poder adorarlo hacerlo digno de adoración [...]" (1952: 335). Así, a través de un "trabajo del yo" que enfoca su autoadoración prospectiva, el individuo egotista intenta descubrir el "íntimo y eterno yo, la idea arquetípica de sí mismo” (1952: 332). Lo que se prefigura aquí es, no por último, una técnica del individuo que se evoca como autosondeo con finalidad autorregulativa.

\section{Trabajos del yo en Poesías, Niebla y el Cancionero}

Ya desde sus primeros poemas, comienzan a vislumbrarse correspondencias con una escritura y un trabajo del yo en la lírica de Unamuno. No es por casualidad que, en la sección titulada "Narrativas" de su libro Poesías, Unamuno dedique un cuento-poema a la figura de Sísifo y que haga funcionar a esta como su alter ego. En su interpretación del mito, el supliciado aparece significativamente como sujeto del ocio que ha superado la pena. Por consiguiente, Unamuno lo escenifica descansando y jugando: "[...] Vencedor del suplicio, está el soberbio / descansando - ¡descansa al fin! - tendido / de una colina sobre el lomo suave, / con paz respira y en la mano tiene / un rodado pedrusco con que juega [...]” (1975: 233). El verso libre capta la nueva libertad de Sísifo y la voz lírica se presenta con expresividad empática.

La figura de Sísifo, curiosamente, también ocupa un lugar central en una carta que Unamuno escribió en 1906 a Francisco Giner de los Ríos. En esta carta la figuración autoidentificadora del personaje mítico se hace más evidente aún, puesto que Unamuno vincula su visión de Sísifo con una experiencia personal, atribuyéndole una función autorregulativa:

Sí, hay que trabajar como si todo hubiera de lograrse. He tenido, para consuelo de mi abatamiento, una especie de revelación del ultramundo platónico, y es que he visto que Sísifo, al cabo de los siglos de siglos de rodar su roca a 
la cumbre, ha gastado la roca, y ha gastado también, aunque mucho menos, la montaña, y a estas horas se encuentra descansando encima de una colina teniendo en la mano, por toda roca de suplicio, un pedrusco con el que juega. Arriba, pues, con mi roca, y cuando caiga, arriba otra vez con ella. Cuando yo la deje, otro la cogerá. (en Inman Fox 1976: 210)

El trabajo del yo se insinúa aquí como actividad ambivalente que se mueve entre el suplicio y el juego. Así, lo paradójico obtiene - una vez más y tal como ya se indicó en relación con el Diario intimo de Unamuno- un alcance ético en tanto que la mediación y la configuración de elementos (aparentemente) opuestos se insinúan como tareas principales del individuo productivamente incongruente consigo mismo. El trabajo del yo se configuraría, por lo tanto, sobre todo en tanto trabajo de la paradoja. Es clave que un programa de autosondeo de esta índole no tiende a eliminar las contradicciones con las que se encuentra, sino que trata, más bien, de hacerlas más finas para poder implementarlas en tanto factores prácticos en el proyecto unamuniano de hacer de la paradoja un motor vivencial. En este sentido, un consejo central que emerge de una escenificación de este tipo de trabajo del yo radica en el "obrarse”, en la continua tarea de una actividad, tanto práctica como mental, que se centra en el individuo y en la que el individuo se centra. Cerezo-Galán vincula esta actividad autocentrada con un proceso de autoconciencia: "Ser-se es tanto hacer por ser, como cobrar conciencia de sí en tanto que se está en la obra de ser” (Cerezo-Galán 1993: 22).

El trabajo del yo, que se ejemplifica a través de la figura de Sísifo, ocupa igualmente un lugar central en otro poema de Poesías, que pertenece al Rosario de sonetos líricos. Data de 1910 y se titula “¡Siémbrate!”:

Sacude la tristeza y tu ánimo recobra, / no quieto mires de la fortuna la rueda / cómo gira al pasar rozando tu vereda / que a quien quiere vivir vidas es lo que le sobra. / No haces sino nutrir esa mortal zozobra / que así en las redes del morir lento te enreda, / pues vivir es obrar y lo único que queda la obra es; echa pues, mano a la obra. // Ve sembrándote al paso y con tu propio arado / sin volver la vista que es volverla a la muerte, / y no a lo por andar sea peso lo andado. // En los surcos lo vivo, en ti deja lo inerte, / pues la vida no pasa al lado de un nublado; / de tus obras podrás un día recogerte. (Unamuno 1987a: 299)

Más explícitamente aún que en sus reflexiones en torno a Sísifo, Unamuno expone aquí las razones del trabajo individual y las enmarca en una implícita retórica de consejo, esto es, ilustra y anticipa las consecuencias positivas a las que puede llevar el "sembrarse", que son la salida de la pasividad y del ánimo decaído, que dará lugar a una noción 
de autonomía del "tú lírico". El trabajo del yo, que se enmarca, fundamentalmente, en el "vivir es obrar", se desarrolla aquí en la apelación de un "tú", estructura casi dialógica que observaremos en otras ocasiones. Además, es un trabajo del ser que se nutre de la contradicción, tal como lo vimos en Sísifo. Así, enfrenta las oposiciones de vivir y morir, de tristeza y fortuna para inclinarse a la buena vida que siempre va a encerrar esta ambivalencia.

Es, asimismo, la noción productiva que subyace en lo contradictorio la que se insinúa como base fundamental de un trabajo del yo en la novela más conocida de Unamuno: Niebla. Este texto, que se publica en 1914, opera de un modo sumamente potencial, puesto que - a manera de una implícita retórica de consejo - sugiere toda una gama de actos y prácticas autorregulativas que el protagonista Augusto Pérez posiblemente emprende. De esta manera, autodiálogos, meditaciones y movimientos físicos se insinúan como instrumentos previstos para manejar sus dudas y contradicciones sin hacerlas desaparecer.

El modo de lo potencial en el que Augusto se mueve subraya permanentemente un posible cambio en el comportamiento de la figura, al mismo tiempo de no efectuarlo. Esta ambivalencia productiva se puede identificar como elemento clave de muchas otras figuras que aparecen en la novela; sin embargo, en Augusto las paradojas resaltan marcadamente, manteniéndose (hecho paradójico en sí), al mismo tiempo, en una constante oscilación entre conciencia y subconciencia de la figura. En consecuencia, el mismo trabajo del yo se insinúa como proyecto sumamente ambivalente.

En el conjunto de la novela, el capítulo 7 destaca formalmente, puesto que consiste casi enteramente en un autodiálogo que Augusto emprende con su perro Orfeo. Este monólogo con tendencias dialogísticas, que se dirige a un "tú" incluyendo a un "nosotros", conforma un marco fundamental en el que se escenifica tanto lo contradictorio de la figura como el consiguiente trabajo de su yo.

Antes que nada, el autodiálogo se nos presenta como un acto introspectivo. Al entrar en diálogo consigo mismo, el yo hablante se torna hacía adentro para atravesarse. Al mismo tiempo, camina por y experimenta el mundo exterior:

¡Ay, Orfeo! Di el gran paso, el paso decisivo: entré en su hogar, entré en el santuario. ¿Sabes lo que es dar un paso decisivo? Los vientos de la fortuna nos empujan y nuestros pasos son decisivos todos. ¿ Nuestros? ¿Son nuestros pasos? Caminamos, Orfeo mío, por una selva enmarañada y bravía, sin senderos. El sendero nos lo hacemos con los pies según caminamos, a la ventura. (Unamuno 2012: 104) 
Es clave que, a partir de este autoatravesamiento, Augusto deambula por toda una cadena de contradicciones. Así, en el habla del protagonista, un oxímoron tras otro escenifica una incongruencia expresa y voluntaria que se delinea como desafío productivo del trabajo del yo.

Además de una generalización de lo específico y una autonomización enajenada, aquí se expone la paradoja de la errancia estratégica. Siendo una paradoja sumamente frecuente no solo en Niebla, sino también en otros textos ensayísticos y ficcionales de Unamuno, expone el movimiento físico, por un lado, en tanto actividad casual que equivale a un desviar y un deambular; por el otro, es este mismo movimiento errante el que se vuelve un acto programático y planeado en el proyecto del trabajo del yo. Así, lo paradójico se expone caminando, es en movimiento donde se trabaja la contradicción.

Además, el confuso caminar de la figura se puede leer como alegoría de movimientos mentales: el pensar digresivo de Augusto, que va proliferándose en tanto movimiento mental tan incongruente como productivo, encuentra aquí una ilustración sugerente. Así, es la coincidencia de digresión física y confusión mental lo que llega a escenificar una productiva incongruencia identitaria en el camino que va trazando el protagonista.

En el texto se nos presenta toda una serie de paradojas en movimiento, que se insinúan como detonantes de un trabajo del yo. Entre ellas, la llamada errancia estratégica figura en un lugar destacado, por lo cual es menester estudiarla en algunos ejemplos más. Así, observamos a Augusto deambular por las calles después de que su amada Eugenia lo ha rechazado:

Quedose Augusto un momento fuera de sí, sin darse cuenta de que existía, y cuando sacudió la niebla de confusión que le envolviera, tomó el sombrero y se echó a la calle, a errar a la ventura. Al pasar junto a una iglesia, San Martín, entró en ella, casi sin darse cuenta de lo que hacía. No vio al entrar sino el mortecino resplandor de la lamparilla que frente al altar mayor ardía. Parecíale respirar oscuridad, oler a vejez, a tradición sahumada en incienso, a hogar de siglos, y andando casi a tientas fue a sentarse en un banco. (2012: 144)

Tal como en la escena anteriormente estudiada, la errancia de Augusto se da aquí como consecuencia de una situación emocional y agitada. Sin embargo, el protagonista se pone a marchar cuando se ha calmado relativamente, lo que parece ser el resultado de una decisión. En ello la función curativa del confuso movimiento físico se hace particularmente presente.

Sin embargo, no es solamente en el movimiento que parece manifestarse un acceso a lo abierto y desplanificado. El errar y la duda incluso se hacen presentes antes de que Augusto diera sus primeros pasos en la novela. Así, cabe recordar una de las primeras escenas, cuando el prota- 
gonista sale de su casa sin saber qué dirección tomar. Decide, finalmente, seguir - de casualidad - al próximo perro que pase por la calle:

Abrió el paraguas por fin y se quedó un momento suspenso y pensando: "Y ahora, ¿ hacia dónde voy?, ¿tiro a la derecha, o a la izquierda?”. Porque Augusto no era un caminante, sino un paseante de la vida. "Esperaré a que pase un perro -se dijo-, y tomaré la dirección inicial que él tome”. (2012: 66)

El hecho de que al final Augusto siga a Eugenia - subvirtiendo y potenciando de esta manera su propia paradoja - puede figurar en este contexto como ilustración de la ironía que se insinúa como otro elemento importante en la concepción del protagonista.

Asimismo, lo irónico se muestra también a nivel del narrador, donde obtiene una función clave en la conformación paradójica del protagonista. De este modo, en el comentario inmerso en la cita que vimos más arriba, se anticipan las oposiciones de un movimiento planeado y un errar que se darían en Augusto: el "caminar” y el "pasear”. El núcleo de la paradoja, entretanto, justamente no radica en el hecho de que las contradicciones se excluyan por completo, tal como quiere hacernos creer el narrador, sino que se mantienen presentes como acciones potenciales en el protagonista. En un nivel más abstracto, podríamos argumentar que una posibilidad negada, aún en su negación, parece vigente por el hecho de que en un momento determinado era una opción real, obteniendo, como tal y ex negativo, una influencia en la opción elegida. Se trataría de una diferenciación según una potencialidad primaria y una potencialidad secundaria.

En la primera escena de la novela, encontramos otro ejemplo más de la concepción paradójica de la figura principal. Aquí el narrador asume una vez más la función del comentarista irónico que crea la ilusión de una contradicción:

Al aparecer Augusto a la puerta de su casa extendió el brazo derecho, con la palma abajo y abierta, y dirigiendo los ojos al cielo, quedose un momento parado en esta actitud estatuaria y augusta. No era que tomaba posesión del mundo exterior, sino era que observaba si llovía. (2012: 65)

El contacto entre figura y mundo se caracteriza aquí, fundamentalmente, como estético. No obstante, la posibilidad de relacionarse de una manera más concreta y práctica con el exterior ("tomar posesión”) se mantiene en su negación. Así, la opción negada se refuerza, al parecer, en la potencialidad secundaria de aquello que también hubiera sido posible. En la medida que ambas opciones mencionadas se mantienen presentes, se articula la necesidad de ponerlas en relación, de trabajarlas y de operar sobre esta paradoja de la simultaneidad opcional. 
Teniendo en cuenta la función global que adquiere lo paradójico en la novela, no es sorprendente que la muerte del protagonista se dé bajo este signo: entre suicidio y muerte natural, lo que presenciamos es una dispersión por medio de lo abundante, puesto que Augusto encuentra su fin comiendo: “[...] abríasele un extraño apetito, una rabia de comer más y más. Y pidió otros dos huevos, y después un bisteque. [...] ¡Siento un apetito voraz! [...] Empezó a devorar el jamón en dulce” (2012: 286 y ss.). Hasta el final, el protagonista se encuentra en un estado entre sujeto y objeto: en momentos le acontece lo que hace y, sobre todo, se trabaja. En esta novela de Unamuno se revela, de esta manera, una concepción figural que esboza al protagonista en tanto potencialidad encarnada del trabajo del yo. Este tipo de personificación de lo permanentemente posible tiende a un mayor grado de aplicación del consejo implícito, tal como lo enfoca la subyacente retórica de consejo en el texto.

El esbozo de un sujeto ético que se trabaja a sí mismo también ocupa un lugar central en el Cancionero, que se subtitula "Diario poético" y que es concebido en el período de 1928-1936. Escrito más de veinte años después de Poesías y tras la publicación Del sentimiento trágico de la vida (1913) y de Niebla, en este libro de poemas - que, según Suárez Miramón, da constancia de una "estructura no lógica sino vital" (1987c: 33)-, la escritura del yo se interrelaciona más explícitamente con una poética de lo impuro, fundándose sobre dos aspectos principales: la evocación de un trabajo autorregulativo, por un lado, y la forma abierta y el estilo en parte aforístico, por el otro.

El libro recién se publica en 1953, sin embargo, su divulgación se prohíbe hasta 1959. En total, el Cancionero contiene 1755 poemas en verso libre, numerados y fechados, por lo cual se sabe que en ciertas fases Unamuno escribió diariamente. La mayor parte del Cancionero la redactó durante su exilio en Hendaya, en 1928 y 1929. Solo una tercera parte la escribe una vez de vuelta en España.

En varios estudios críticos se ha destacado el valor de este libro poético, el más extenso de Unamuno. Así, Suárez Miramón (1987c: 25) ve plasmada ahí la base de la filosofía existencialista del autor, y Vivanco (1980: 359) llama la atención sobre el efecto catártico de los poemas, abriendo la recepción, de esta manera, a vías interpretativas que enfocan, sobre todo, su lado ético.

$\mathrm{Si}$ en otros escritos Unamuno se había imaginado a través de la concepción de sus figuras, en el Cancionero, así lo afirma Vivanco, "[...] se va a soñar a través de sí mismo, también como criatura suya. Se va a enajenar hacia adentro, ensimismándose" (1980: 361). En esta objetivización autorreflexiva insinuaría, no por último, el potencial de cierto trabajo autorregulativo del yo. Este se desarrollará, como veremos, a través de un ritmo y una expresividad vitales, configurando una poética de lo impuro, llena de vida. 
El prólogo del Cancionero ya es sumamente revelador en cuanto a la interrelación de escritura del yo y escritura de la impureza, de ahí que Unamuno lo utilice para fundar y exponer su poética de manera más explícita - sin dejar de volver a su crítica a la estética modernista -. Al mismo tiempo, vincula lo impuro con un discurso sobre su identidad inconmensurable, que hace recordar su exploración autocentrada en el Diario intimo.

Primero, Unamuno se escenifica como un ser doblemente desterrado. Habla sobre sí mismo en tanto individuo exiliado y dice: "Me hallo en el destierro, fuera, aunque a la vista de mi España [...]” (1987c: 47). Además, se expone como observador de su propia persona: "Y hecho teatro de mí mismo [...] tratando de descubrirme a mí mismo, de conocerme [...]" (1987c: 47). Durante y a través de esta autoinspección elabora una clara noción de identidad:

Sí, lo que sentimos como espíritu de independencia y llamamos así, es el sentimiento de nuestra identidad; ser independiente es ser idéntico, es ser igual a sí mismo, es ser uno mismo, es ser persona continua. Y como la infinitud no es más que continuidad - lo infinito es lo continuo, lo concreto- la persona continua es infinita e inconmensurable. (1987c: 66)

En esta definición de identidad, que se concibe, significativamente, desde y para un "nosotros", reclamando, así, un mayor grado de aplicación, resulta ser la búsqueda identitaria misma la que opera como elemento básico. Así, es la errancia permanente y duradera - la errancia estratégica que estudiamos en Niebla - la que puede dar un fundamento sólido y, al mismo tiempo, dinámico al yo. Enfrentar el constante cambio y vivir de él es la tarea existencialista que Unamuno retoma de Nietzsche y también de Kierkegaard para integrarla en su concepción del trabajo del yo. Tanto Nietzsche como Kierkegaard centran su filosofía de la existencia en torno a la idea de que el sujeto está en un permanente proceso de autoconsolidación. Así, la existencia misma equivale a una tarea y un experimento permanentes que ofrecen, al mismo tiempo, toda una gama de potencialidades que el individuo puede adoptar e incorporar (cf. Meyer 1993: 142; Thurnherr/Hügli 2007: 88).

La poética de lo impuro figura como reflejo y detonante de este elogio de lo continuo e infinito, porque en su manejo de lo heterogéneo tiende a la duración. Unamuno lo explica así: "[...] el oro puro es deleznable y poco duradero. Una cierta cuantía de aleación de cobre o plata le da al oro dureza y con ella duración. Y por esto la poesía impura, con aleación de retórica, de lógica, de dialéctica, es más dura y más duradera que la poesía pura" (1987c: 64).

Es interesante que el vínculo entre escritura del yo y poética de lo impuro desemboque en el Cancionero no solamente en un trabajo auto- 
rregulativo, sino también en una retórica del consejo que puede ser dirigida tanto a Unamuno mismo como a sus lectores. En este sentido, el ensimismamiento unamuniano parece trascender hacia un contacto con el otro, dando lugar a una serie de diálogos o autodiálogos. Así, se retoma la estructura dialógica que observamos tanto en Poesías como en Niebla, donde, respectivamente, cumple una función parecida de animar al yo y a su interlocutor en el proyecto de un trabajo autorregulativo. Veamos algunos ejemplos.

En el poema número 36, que data del 15 de marzo de 1928, Unamuno reflexiona acerca del valor de la introspección: "Entre el destino y la suerte / has de escoger; a la par / no lograrás abarcarlos / o ser tú o no ser más. / Tu porvenir sacrifica / a tu propia eternidad, / pues así sólo has de hacerte / todo un hombre de verdad. / ¡Adéntrate!” (1987c: 88). Es interesante que, tal como vimos en el pasaje analizado de Niebla, la introspección se insinúa aquí como instrumento que puede ayudar a trabajar y a mediar entre opciones que tienden a excluirse y que son aquí el destino y la suerte. ${ }^{5}$

Ya en un texto más temprano, titulado “¡Adentro!”, que data de 1900, Unamuno había practicado esta retórica del consejo. Aparte de un elogio de la introspección, el breve texto presenta la errancia como una actitud prospectiva que se abre a la vida y sus contingencias. Con esto, puede leerse como precedente del andar tan confuso como planeado que Augusto nos presenta en Niebla y que se va a prolongar hasta el prefacio del Cancionero.

Así, en el breve ensayo que se escenifica como carta ficticia dirigida a un interlocutor imaginario, el movimiento físico se celebra como prospectiva dinámica autorreveladora que hace uso de lo desconocido atribuyéndole un valor productivo, y la errancia estratégica se esboza como elemento clave de un trabajo del yo que se abre a la contingencia de la vida. La anticipación y planificación del futuro, así lo predica el remitente, impedirán, finalmente, la disposición abierta hacia el cambio y lo imprevisible. De hecho, son la errancia y la intuición las que, por consiguiente, se insinúan como consejos sugerentes en esta carta lúdica:

Hay en tu carta una cosa que no me gusta, y es ese empeño que muestras ahora por fijarte un camino y trazarte un plan de vida. ¡Nada de plan previo, que no eres edificio! No hace el plan a la vida, sino que ésta lo traza viviendo. No te empeñes en regular tu acción por el pensamiento; deja más bien que aquélla te forme, informe, deforme y trasforme éste [...]. (Unamuno 1951: 84)

${ }^{5}$ Villalobos de Piccone se refiere al "ejercicio de interiorización" (1998: 44) que subyace en el autodiálogo que concibe Unamuno. Así, el acto introspectivo se evoca - una vez más - como un elemento importante en el proyecto del trabajo individual. 
Es clave que, aparte de cierta actitud ante la vida, la errancia estratégica posibilita procesos no solo de autorregulación, sino también de autoconocimiento: "[...] vas descubriéndote conforme obras [...]. Esto es caminar sin plan previo, y dejando que el plan surja. Y es lo más orgánico, pues lo otro es mecánico; es lo más espontáneo" (Unamuno 1951: 86).

Asimismo, en el Cancionero la retórica de consejo se alterna, constantemente, con un desdoblamiento autorreflexivo. A finales del año 1928, Unamuno lo formula en dos poemas aforísticos. El primero, que data del 30 de noviembre, dice: "Singularizarme? Vamos... / Somos todos de consumo / y en la piña que fraguamos / yo soy nos-otro, nos-uno" (1987c: 316). El segundo, que escribe una semana después, pregunta: “Tú y yo? / Yo contigo, tú conmigo; / Tú y yo. / Yo y tú hace el amigo; / no es más que uno; / te lo asegura Unamuno" (1987c: 323). En estos breves ejemplos se ilustra, particularmente, la cadena conceptual de escritura del yo, trabajo autorregulativo y poética de lo impuro. Además, la formulación de preguntas no solo corrobora el tono expresivo y en parte irónico, sino que crea, una vez más, un "nosotros” en el proyecto de la individualidad ética.

En estos poemas de tendencia lúdica, se marca un distanciamiento productivo entre "uno" y "otro", entre "tú" y “yo", distanciamiento que se insinúa como punto de partida del trabajo individual. Es interesante que en el poema número 939, escrito el 23 de marzo de 1929, nos encontramos con otra variante más de la autodistancia, la que se extiende entre "yo" y “yo":

¡No logro encontrarme yo / este yo, pobre de mí! / ¡dentro no oigo sino no! / ¡fuera es donde suena: sí! / Mas cuando busco un amigo / o lo rebusco, mejor / tengo que contar conmigo, / que Tú me diste, Señor. / Y en esta gran confusión / ni sé bien lo que no sé; / recovecos de pasión; / tú, mi Yo, perdóname. (1987c: 457)

Es clave que el yo, aunque fue dado por Dios, puede encontrarse solamente a través de sí mismo. El yo es el amigo más cercano (y, al mismo tiempo, más lejano) en la tarea de buscar y rebuscarse, en el desafío de trabajarse continuamente, en la exigencia de "[...] la voluntad de hacer, para ser” (Villalobos de Piccone 1998: 52).

Para resumir y concluir, podemos afirmar que, tanto en el trabajo paradójico del yo que se da en Poesías, en Niebla y en el ensayo ;Adentro! como en la escritura impura del yo que analizamos en el Cancionero, Unamuno circunda, sin duda, un yo autobiográfico que se busca para consolidarse en un continuo proceso de autocuestionamiento y autorregulación. Sin embargo, no se mantiene en este círculo estrictamente cerrado del trabajo individual; al contrario, lo trasciende en varios sentidos. 
De ahí que, en su escritura del yo, Unamuno opere en un campo transgenérico que conecta los respectivos poemas, así como los textos ensayísticos y ficcionales, entre sí, resaltando, además, la composición heterogénea en el interior de cada uno de los fragmentos estudiados. En el verso libre, en la tendencia hacia el aforismo y la idea ensayística, así como en el gesto conceptual y la dialoguicidad expresiva, se reúne, sobre todo en los poemas, una multitud de aspectos que traspasan la categorización genérica.

En este sentido, la heterogeneidad lleva en sí el germen de una poética de lo impuro, ya que se presta tanto a lo dialéctico como a lo aleatorio. Entendido así, lo impuro se insinúa como instrumento adecuado en la búsqueda de un yo que siempre se escapa, mostrándose en mutaciones interminables y nunca fijables, puesto que ilustra la dinámica subyacente sin eliminarla.

Otro motor trascendente de la poesía unamuniana radica en la exteriorización de la autopoiesis. Esta se lleva a cabo a través de la concepción de un destinatario personal o personificado a quien se dirigen el trabajo del yo y la retórica del consejo que Unamuno concibe tanto en el Cancionero - vislumbrándose ya en Poesías - como en Niebla. Así, se realiza la integración de un otro, ya sea este imaginario o real, ya sea intra- o extraindividual, a través de estructuras dialógicas o autodialógicas. Es quizás este gesto integrativo lo que se hubiera prestado a hacer de lo circundante lo plenamente circulante a nivel transnacional. Sin embargo, a ello se opuso, así parece, la egolatría unamuniana que, si bien mira hacia el otro, más se ocupa de observarse a sí misma.

\section{BiBLIOGRAFÍA}

Alvar, Manuel (1975): “Prólogo”. En: Unamuno, Miguel de: Poesías. Barcelona: Labor, pp. 7-46.

Cerezo-Galán, Pedro (1993): “Introducción”. En: Unamuno, Miguel de: Del sentimiento trágico de la vida. Madrid: Espasa-Calpe, pp. 9-44.

Chávez, Julio César (1964): Unamuno y América. Madrid: Ediciones Cultura Hispánica.

Foucault, Michel (2007): Ästhetik der Existenz. Schriften zur Lebenskunst. Frankfurt am Main: Suhrkamp.

García Blanco, Manuel (1964): América y Unamuno. Madrid: Gredos.

InMAN Fox, Edward (1976): La crisis intelectual del 98. Madrid: Editorial Cuadernos para el Diálogo.

Meyer, Theo (1993): "Nietzsche als Paradigma der Moderne”. En: Piechotta, Hans Robert/Wuthenow, Ralph-Rainer/Rothemann, Sabine (eds.): Die literarische Moderne in Europa. Bd. 1: Erscheinungsformen literarischer Prosa um die Jabrbundertwende. Opladen: Westdeutscher Verlag, pp. 136-170. 
Rull Fernández, Enrique (1984): El modernismo y la generación del 98. Madrid: Editorial Playor.

SuÁrez Miramón, Ana (1987a): “Introducción a la poesía de Unamuno”. En: Unamuno, Miguel de: Poesía completa, 1. Madrid: Alianza Editorial, pp. 9-35.

— (1987b): “Introducción”. En: Unamuno, Miguel de: Poesía completa, 2. Madrid: Alianza Editorial, pp. 9-28.

— (1987c): "Introducción”. En: Unamuno, Miguel de: Poesía completa, 3. Madrid: Alianza Editorial, pp. 9-37.

Thurnherr, Urs/HüGlI, Anton (2007): Lexikon Existenzialismus und Existenzphilosophie. Darmstadt: WGB.

Unamuno, Miguel de (2012): Niebla. Madrid: Alianza Editorial.

- (1993): Del sentimiento trágico de la vida. Madrid: Espasa-Calpe.

- (1987a): Poesía completa, 1. Madrid: Alianza Editorial.

- (1987b): Poesía completa, 2. Madrid: Alianza Editorial.

- (1987c): Poesía completa, 3. Madrid: Alianza Editorial.

- (1975): Poesías. Barcelona: Editorial Labor.

- (1970): Diario intimo. Madrid: Alianza Editorial.

- (1958): “El modernismo". En: García Blanco, Manuel (ed.): Obras Completas. Tomo XI. Meditaciones y otros escritos. Madrid: Afrodisio Aguado, pp. 13031304.

— (1952): "Nuestra egolatría de los del 98”. En: García Blanco, Manuel (ed.): Obras completas. Tomo V. De esto y aquello. Madrid: Afrodisio Aguado, pp. 331-337.

- (1951): Paisajes y ensayos. Obras completas, I. Madrid: Afrodisio Aguado.

Villalobos de Piccone, Delia (1998): Soledad y esperanza en el mundo poético de Miguel de Unamuno. Buenos Aires: Ediciones Corregidor.

Vivanco, Luis Felipe (1980): "El mundo hecho hombre en el Cancionero de Unamuno”. En: Sánchez-Barbudo, Antonio (ed.): Miguel de Unamuno. Madrid: Taurus, pp. 349-374.

YNDURÁin, Francisco (1980): “Unamuno en su poética y como poeta”. En: SánchezBarbudo, Antonio (ed.): Miguel de Unamuno. Madrid: Taurus, pp. 323-347. 